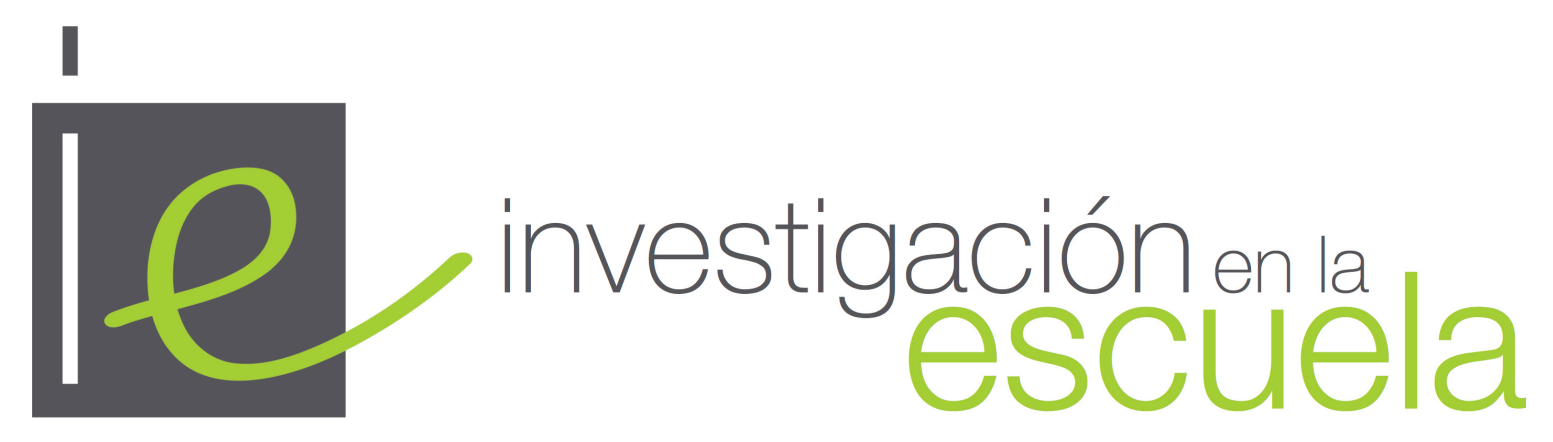

Revista internacional de investigación e innovación educativa

\title{
El franquismo en el libro de texto. Un análisis crítico de tres manuales escolares para $4^{\circ}$ de ESO en Andalucía
}

\author{
José Carlos Mancha Castro \\ Universidad de Huelva \\ España
}

Citación: Mancha Castro, J.C. (2019). El franquismo en el libro de texto. Un análisis crítico de tres manuales escolares para $4^{\circ}$ de ESO en Andalucía. Investigación en la Escuela, 99, 1-15.

doi: http://dx.doi.org/10.12795/IE.2019.i98.01

Resumen: Este artículo analiza si el avance del conocimiento científico universitario sobre el franquismo se refleja en el tema dedicado a este período en tres manuales escolares de $4^{\circ}$ de ESO producidos para Andalucía. La selección de la muestra se concretó siguiendo el criterio de la ideología de la editorial, centrándonos en tres manuales de corte conservador y liberal. Se realiza un análisis crítico del contenido de cada uno de ellos y se reflexiona sobre el conocimiento científico que presentan. Los resultados muestran la necesidad de abordar una revisión conceptual de las informaciones contenidas en los textos y su adecuación a los avances del conocimiento científico sobre el franquismo a nivel universitario.

Palabras clave: "Franquismo"; "libro de texto"; "historia"; "enseñanza de la historia"; "dictadura"; "educación secundaria obligatoria".

Francoism in the textbook. A critical analysis of three school textbooks for the 4th year of Compulsory Secondary Education (ESO) in Andalusia 


\begin{abstract}
This article analyses whether the advance of university scientific knowledge on Francoism is reflected in the theme dedicated to this period in three 4th ESO school textbooks produced for Andalusia. The selection of the sample was made following the criteria of the editorial's ideology, focusing on three conservative and liberal textbooks. A critical analysis of the content of each of them is carried out and the scientific knowledge they present is reflected upon. The results show the need to undertake a conceptual revision of the information contained in the texts and their adaptation to the advances in scientific knowledge on Francoism at university level.
\end{abstract}

Key words: "Francoism"; "textbook"; "history"; "history teaching"; "dictatorship"; "compulsory secondary education".

Le franquisme dans les manuels scolaires. Une analyse critique de trois manuels scolaires pour la quatrième année de l'Enseignement Secondaire Obligatoire en Andalousie

Resumè: Cet article analyse si l'avancée des connaissances scientifiques universitaires sur le franquisme se reflète dans le thème consacré à cette période dans trois manuels scolaires du 4ème ESO produits pour l'Andalousie. La sélection de l'échantillon a été faite selon les critères de l'idéologie de l'éditorial, en se concentrant sur trois manuels conservateurs et libéraux. Une analyse critique du contenu de chacun d'entre eux est effectuée et les connaissances scientifiques qu'ils présentent font l'objet d'une réflexion. Les résultats montrent la nécessité d'entreprendre une révision conceptuelle des informations contenues dans les textes et leur adaptation aux progrès des connaissances scientifiques sur le franquisme au niveau universitaire.

Mots-clés: "Franquisme"; "manuel scolaire"; "histoire"; "enseignement de l'histoire"; "dictature"; "education secondaire obligatoire".

\title{
Introducción y estado de la cuestión
}

El estudio y análisis de los manuales escolares en España constituye uno de los tópicos o líneas de investigación clásica en la Didáctica de las Ciencias Sociales (Valls Montés, 2001a, 2001b, 2007b; Prats, 2011; Rodríguez Pérez y Solé, 2018). Hace más de tres lustros, Prats (2003) definió los cinco ámbitos investigativos mayoritarios en la disciplina que, según Miralles Martínez, Molina Puche y Ortuño Molina (2011), aún hoy continúan siendo las principales líneas referenciales para las investigaciones desarrolladas en el área. Estas cinco líneas son: 1) estudios sobre diseño y desarrollo curricular en sus diversas etapas, áreas y disciplinas educativas; 2) construcción de conceptos y elementos que centren el contenido relacional y polivalente de la Didáctica de las Ciencias Sociales; 3) estudios sobre comportamiento y desarrollo de la profesionalidad docente en lo referente a la enseñanza de la Historia, Geografía y Ciencias Sociales; 4) investigaciones ligadas a las concepciones de la Historia y la Geografía u otras Ciencias Sociales entre el alumnado, y la evaluación de los aprendizajes; 5) investigaciones sobre la Didáctica del Patrimonio.

Las investigaciones sobre los libros de texto se encuadrarían en la línea de los estudios sobre diseño y desarrollo curricular en diversas etapas, áreas y disciplinas educativas, sin lugar a dudas uno de los campos que ha sido objeto de mayor número de investigaciones y sobre el que han corrido ríos de tinta. Porque lo cierto es que el uso del libro de texto continúa siendo una práctica generalizada en todas las etapas educativas en España, siendo un instrumento muy relevante en el desarrollo de la praxis profesional de muchos docentes e influyendo en ella de una manera u otra (López Hernández, 2007; Braga Blanco y Belver Domínguez, 2016; Fernández Palop y Caballero García, 2017). No en vano, Prats (2011) asegura que más de un noventa por ciento del profesorado utiliza el manual escolar como principal recurso en el aula. 
En la literatura científica sobre la temática, la mayoría de los autores no han discriminado entre el uso de los conceptos manual escolar, libro de texto o libro escolar (Mondragón Mullor, 2013), utilizando éstos como sinónimos y prescindiendo de los debates en torno a la terminología propuestos por los “estudios precursores" -en palabras de Tosi (2011, p. 471)- de Puget (1963), Choppin (1980), Hamilton (1990) o Johnsen (1996), entre otros ${ }^{1}$. Según Braga Blanco y Belver Domínguez (2016, pp. 201-202), las funciones que cumplen los libros de texto en el marco del desarrollo curricular resultan imprescindibles para entender su papel predominante en las escuelas. Estas funciones son: 1) realizan una determinada selección cultural, ya que transmiten una determinada visión de la realidad, representando el saber oficial y presentándose como una fuente de información "legítima"; 2) son un producto de consumo que es necesario analizar a la luz de los procesos de producción y comercialización de los mismos; 3) se convierten en el currículum real, ya que son un producto escolar específico en el que se materializa el currículo en todas sus dimensiones, configurándose como la más importante propuesta curricular que interpreta y concreta el currículum oficial para el profesorado.

Los diversos estudios sobre libros de texto han generado diferentes líneas de investigación y actuación, que se pueden clasificar en base a las diferentes temáticas que han sido objeto de análisis. Johnsen (1996) clasificó los estudios en tres grupos: 1) los focalizados en la investigación sociohistórica e ideológica y los análisis centrados en el abordaje de los contenidos; 2) los focalizados en el uso, la didáctica y los métodos de enseñanza; 3) los focalizados en las condiciones de producción y circulación y el mercado editorial ${ }^{2}$. Más recientemente, Negrín (2009, pp. 189-196) ha propuesto una clasificación que refleja las diferentes temáticas analizadas en los trabajos de investigación realizados sobre libros de texto: 1) línea relacionada con las políticas editoriales, económicas y culturales y los procesos de diseño, elaboración, circulación y recepción de los libros de texto; 2) línea que se ocupa de la historia de los manuales escolares y su mutación bajo las influencias de las tecnologías de la información y de la comunicación; 3) línea dirigida a los estudios críticos, históricos e ideológicos acerca del contenido de los manuales escolares; 4) línea de los estudios formales, lingüísticos y discursivos, referidos a la legibilidad, comprensión, presentación y adecuación didáctica; 5) estudios dirigidos al análisis del papel de los libros de texto en el diseño de los criterios evaluación y la selección de los materiales curriculares y a las opiniones y demandas del profesorado ${ }^{3}$. El análisis que aquí presentamos se insertaría en la línea 1 definida por Johnsen (1996) y en la línea 3 de la clasificación aportada por Negrín (2009), esto es, se trata de un trabajo crítico sobre análisis del contenido de manuales escolares y su vertiente socio-histórica e ideológica.

Como bien se especifica en la Web de The Georg Eckert Institute for Internacional Textbook Research, los libros de texto, en tanto portadores del conocimiento y la información que desde los centros de poder de una generación se desea transmitir a la siguiente, se encuentran con frecuencia en el centro de la controversia política ${ }^{4}$. La política referente al libro de texto, al igual que la del currículo, es definida por el sistema educativo. Para Castillejo Cambra, se trata de un sistema inserto

\footnotetext{
${ }^{1}$ En este sentido, Johnsen (1996) establece una clara distinción entre libro de texto y libro escolar. Para este autor, un libro de texto (textbook) sería aquel que ha sido escrito, diseñado y producido para su uso específico en la enseñanza. Por su parte, el libro escolar (schoolbook) sería todo aquel libro que puede ser empleado como material de apoyo en el proceso de enseñanza pero que no ha sido enfocado a la finalidad de servir a las secuencias pedagógicas. Para ahondar en los debates pedagógicos acerca de las conceptualizaciones de manual escolar, libro de texto o libro escolar, véase también Fernández Palop y Caballero García (2017, pp. 203-205).

2 Véase Tosi (2011).

3 Véase también Mondragón Mullor (2013, pp. 35-36)

${ }^{4}$ En la propia Web del citado instituto se puede leer: "The condensed and canonical character of the information included in school educational media gives it key significance in academia, policy and education. Textbooks, as carriers of the knowledge and information that one generation wishes to pass on to the next, frequently find themselves at the centre of political controversy". Véase http://www.gei.de/en/institute.html.
} 
en una estructura democrática que propicia cierta polifonía entre varias tendencias ideológicas (en el caso español: liberalismo, catolicismo, izquierdismo, catalanismo, castellanismo, etc.), pero que no entra a cuestionar las ocultaciones historiográficas de ciertos manuales ni analizar los conflictos ideológicos generados en la Historia Contemporánea. En palabras de suyas, este "alto grado de indefinición del sistema democrático puede ser tan ideológico como el adoctrinamiento de las dictaduras. El remedio a los males de la indefinición es que la historiografía escolar asuma los avances de la historiografía profesional, pierda el miedo a los tabúes, destruya mitos, no olvide las virtudes de la historia contrafactual y se decida claramente por la reeducación” (2009, p. 49).

Según Puelles Benítez (1997), desde que se instauró el Ministerio de Instrucción Pública en España, se ha oscilado entre la libertad del docente para escoger el libro de texto, la opción de la lista de manuales elaborada por el Ministerio y el sistema de texto único. "El fracaso del texto único en los albores de la dictadura de Franco se debió a la presión editorial y a la necesidad de dar cabida a todas las ideologías que la sustentaban: monarquismo alfonsino, carlismo, falangismo... Así, la política del libro escolar facilitaba la integración de las distintas elites, lo mismo que hoy permite integrar distintas tradiciones (catolicismo, liberalismo...), útiles para la conservación del sistema, más que para su transformación. [...] Cada editorial conserva una línea ideológica: SM se define por la fidelidad católica; Vicens Vives por el liberalismo; Santillana o ECIR por un liberalismo más avanzado; Alhambra gira más a la izquierda... Pero hay situaciones complejas" (Castillejo Cambra, 2009, p. 49).

Entre las investigaciones en Didáctica de las Ciencias Sociales que se han centrado en analizar el tema de los manuales escolares de Historia en España destacan las aportaciones de Prats (2011), Valls Montés (2001a, 2001b y 2007b) y, especialmente, las derivadas de los proyectos de investigación en los que ha participado el Centro MANES ${ }^{5}$. Prats (2011) ha analizado los criterios mayoritariamente utilizados por el profesorado para la elección del manual escolar en la asignatura de Historia. Valls Montés (2001a, 2001b) ha centrado su mirada en la destacada atención que los investigadores del ámbito universitario han mostrado en el análisis de los manuales escolares, vista la creciente importancia que los mismos han ido ganando en el ámbito educativo. Asimismo, ha ahondado la complejidad que han ido adquiriendo esos análisis críticos, así como los nuevos retos planteados por las investigaciones más innovadoras en ese campo. También Valls Montés (2007b) ha reflexionado sobre las dificultades del uso didáctico de las imágenes en los libros de texto de Historia. Castillejo Cambra (2009) ha realizado un interesantísimo análisis sobre el contenido ideológico latente y manifiesto en los manuales escolares de la asignatura de Historia. Campos Pérez (2010), por su parte, ha problematizado la idea de España reflejada en los libros de texto de Historia, conformando toda una iconografía que muestra y debate las diferentes concepciones sobre el relato nacional español desde la Segunda República a los años ochenta del siglo pasado. Recientemente, Rodríguez Pérez y Solé (2018) han abordado una tarea novedosa y necesaria: la comparación de los manuales escolares de Historia en España y Portugal, tanto en las etapas de educación primaria como secundaria.

El caso del análisis de la dictadura franquista en los manuales escolares de Historia en España ha sido centro de atención de Valls Montés (2007a), Díez Gutiérrez (2014) y, más

${ }^{5}$ El Centro de Investigación MANES (Manuales Escolares) es un centro interuniversitario e interdisciplinario dedicado al estudio histórico de los manuales escolares de España, Portugal y América Latina, especialmente en los siglos XIX y XX. Fue creado en 1992, siendo impulsado por el Departamento de Historia de la Educación y Educación Comparada de la UNED e inspirado en su homólogo francés, el Institut National de Recherche Pédagogique, creado en 1980 y dirigido por Alain Choppin. Las tareas desarrolladas por MANES y sus objetivos específicos pueden ser consultados en: http://www.centromanes.org/. Asimismo, su base de datos está integrada a nivel internacional en el catálogo colectivo International Textbook Catalogue, un proyecto coordinado por The Georg Eckert Institute for International Textbook Research (Braunschweig, Alemania). 
recientemente, de Fuertes Muñoz (2018). El primero ha dibujado los avances historiográficos y didácticos conseguidos hasta el momento, así como las deficiencias de muchos de los planteamientos esbozados desde la perspectiva de un tratamiento realmente democrático y reconciliatorio de los mismos. A través de un análisis crítico del discurso, Díez Gutiérrez (2014) ha investigado cómo se reflejan los contenidos de diferentes aspectos correspondientes al período de la posguerra civil y, especialmente, los relacionados con la represión de la dictadura franquista y la oposición y lucha antifranquista, en los libros de texto de Historia de España de $2^{\circ}$ de Bachillerato. Por su parte, Fuertes Muñoz (2018) ha analizado el tratamiento de la dictadura franquista en los manuales escolares españoles tanto de educación primaria, secundaria como del bachillerato en los últimos veinte años, partiendo de la premisa de que el tratamiento educativo de un pasado categorizado como conflictivo y de actualidad -como es el caso del franquismo- debe preocupar a la comunidad de investigadores y profesores de Historia, en tanto en cuanto tiene profundas repercusiones potenciales en la construcción de las identidades sociopolíticas de las nuevas generaciones. En este sentido, aunque el autor no pone en duda los avances producidos, focaliza su atención en las carencias metodológicas, epistemológicas e interpretativas que aprecia en los libros de texto publicados bajo la vigencia de las tres últimas leyes educativas: LOGSE, LOE y LOMCE.

Nuestra pretensión no es tan ambiciosa como los objetivos marcados por los estudios precedentes. En lugar de hacer un análisis de los diferentes manuales escolares producidos y utilizados para lo largo y ancho del Estado español, hemos querido focalizar la mirada en aquellos libros de texto adaptados al ámbito educativo andaluz por tres editoriales concretas. Nuestro objetivo es analizar cómo el avance del conocimiento científico universitario sobre el franquismo se ve o no reflejado en los contenidos conceptuales propuestos en las unidades temáticas de la dictadura de Franco en tres manuales de corte liberal y conservador, uno de ellos producido en los tiempos de la LOGSE y dos de ellos en los tiempos de la LOMCE. Es decir, nuestro trabajo pretende contestar a la siguiente pregunta de investigación: ¿se refleja el avance del conocimiento científico universitario sobre el franquismo en los contenidos conceptuales que se ofrecen en los manuales escolares de $4^{\circ}$ curso de ESO de tradición liberal y conservadora producidos para Andalucía?

\section{Metodología empleada y criterios de selección}

La metodología empleada en esta investigación de carácter documental se basó en un tratamiento de los datos de tipo cualitativo, realizándose un análisis crítico del contenido (Van Dijk, 1997) siguiendo el método de comparación constante y de saturación teórica (Glaser y Strauss, 1967; Strauss y Corbin, 1998). Se trata de un modelo de análisis tradicional, ampliamente utilizado en estudios de Sociología crítica e interpretativa y en el ámbito de la investigación en Didáctica. Nuestro trabajo supone una revisión crítica del discurso-contenido de libros de texto, revisión focalizada en las unidades sobre el franquismo propuestas por tres manuales escolares específicos, producidos para $4^{\circ}$ curso de Educación Secundaria Obligatoria del contexto educativo andaluz en distintos años.

Esta mirada focalizada se debía a la imposibilidad de abordar todos los ángulos y perspectivas desde los que se podrían analizar estos materiales didácticos y, mucho menos, toda la amalgama de manuales producidos para los distintos ámbitos autonómicos y en distintos períodos. Decidimos escoger el franquismo como unidad de análisis por representar la línea de investigación en la que hemos centrado nuestro interés principal y nuestros esfuerzos académicos durante los últimos años. Por su parte, nos decantamos por escoger libros de textos producidos para Andalucía por ser la comunidad en la que hemos desarrollado nuestra actividad docente e investigadora. En particular, nos interesaba estudiar cómo se reflejan los contenidos sobre la temática en editoriales 
específicas, debido, también, a la imposibilidad de analizar la cuestión en todas las editoriales existentes, un propósito que trascendería los límites de este artículo.

Por ello, el criterio principal que se aplicó para la selección de la muestra de manuales que serían sometidos a revisión fue el de la ideología de la editorial. En este sentido, pretendíamos centrar la mirada en libros de texto de editoriales escoradas a la corriente ideológica de la derecha debido a la naturaleza ideológico-política del régimen de Franco, unidad temática que iba a ser analizada, con evidentes connotaciones ligadas al espectro ideológico derechista, representando, aún hoy, un tema en conflicto permanente, expresado en diferentes debates y discursos políticos de nuestros días. Así, decidimos escoger dos manuales ligados a tradiciones liberales y un tercero ligado a la tradición de la democracia cristiana-católica, es decir, que nos regimos por la selección de libros de texto de editoriales de corte conservador.

Otro criterio que también se aplicó para la selección muestral fue que, al menos, dos de los libros debían haber sido producidos al amparo de leyes educativas diferentes y aprobadas por gobiernos de distinto partido e ideología. La intención fue comparar el contenido de un manual ya en desuso escolar, producido en tiempos de la LOGSE -ley educativa elaborada por un gobierno socio-liberal o socialdemócrata-, con el de dos manuales escolares recientes, producidos en tiempos de la LOMCE -ley educativa elaborada por un gobierno liberal-conservador. Asimismo, decidimos seleccionar dos manuales de editoriales ampliamente utilizadas en los centros escolares -Anaya y Vicens Vives- y otro manual menos hegemónico, producido por una editorial estrechamente ligada a una comunidad educativa concreta de ideario católico, Edelvives, editorial de cabecera de los Hermanos Maristas ${ }^{7}$ Los manuales que constituyen la citada muestra se recogen en la Tabla 1.

Tabla 1

Muestra de la investigación

\begin{tabular}{|c|c|c|c|c|}
\hline Editorial & $\begin{array}{l}\text { Año de } \\
\text { publica- } \\
\text { ción }\end{array}$ & Autores & $\begin{array}{c}\text { Corriente } \\
\text { ideológica de la } \\
\text { editorial }\end{array}$ & $\begin{array}{c}\text { Ley } \\
\text { educativa } \\
\text { en vigor } \\
\end{array}$ \\
\hline Vicens Vives & 2001 & $\begin{array}{l}\text { Fernández, A., Llorens, } \\
\text { M., Ortega, R., García, } \\
\text { M., Gatell, C. y Roig, J. }\end{array}$ & Liberalismo & LOGSE \\
\hline Anaya & 2016 & $\begin{array}{l}\text { Burgos, M. y Muñoz- } \\
\text { Delgado, M. C. }\end{array}$ & Liberalismo & LOMCE \\
\hline Edelvives & 2017 & García, M. y Loza, B. & $\begin{array}{l}\text { Humanismo y } \\
\text { democracia } \\
\text { cristiana }\end{array}$ & LOMCE \\
\hline
\end{tabular}

El problema de investigación principal al que se pretendía dar respuesta se concretaba -como se ha dicho- en la siguiente pregunta de investigación: ¿`se refleja el avance del conocimiento científico a nivel universitario de las últimas tres décadas en los contenidos conceptuales propuestos por libros de texto producidos en tiempos de la LOGSE y de la LOMCE por editoriales de tradición

\footnotetext{
${ }^{6}$ Damos aquí la connotación de conservadora a tres editoriales cuyos contenidos coadyuvan a la conservación del sistema económico-político sobre el que se sustenta el Estado español de nuestros días, y que supone el propósito de la línea ideológica seguida por la mayoría de las editoriales, más centradas en la conservación del sistema que en su transformación, tal y como exponía Castillejo Cambra (2009).

${ }_{7}$ Díez Gutiérrez (2014) señala que las diez editoriales de ámbito nacional más utilizadas en Ciencias Sociales en los diferentes cursos de ESO y Bachillerato son: Oxford, McGraw Hill, SM, Vicens Vives, Santillana, Anaya, Laberinto, Bruño, Ecir y Akal.
} 
liberal y conservadora para $4^{\circ}$ curso de ESO en el ámbito educativo andaluz? En este sentido, la forma de proceder para el análisis de la cuestión planteada fue la siguiente: 1) consulta, lectura y estudio de diversos manuales universitarios de especialistas en el franquismo producidos durante los últimas tres décadas; 2) lectura minuciosa, estudio y reflexión del contenido del conocimiento científico propuesto por cada una de las unidades didácticas sobre el franquismo de los libros de texto de la muestra seleccionada; 3) producción del texto de análisis crítico sobre cada uno de ellos. Para la producción del texto crítico se atendió a dos dimensiones o categorías de análisis: a) la división y estructura del conocimiento científico propuesto en la unidad didáctica; b) los aspectos deficientes y/o las informaciones imprecisas, silenciadas u ocultadas en el desarrollo del conocimiento científico propuesto en la unidad didáctica.

\section{Análisis crítico del contenido de la unidad seleccionada en tres libros de texto de $4^{\circ}$ de ESO para Andalucía}

En este apartado, exponemos el trabajo de revisión crítica acerca de la plasmación y reflejo o no del avance del conocimiento científico universitario sobre el franquismo en el contenido de la temática abordada en los tres manuales escolares seleccionados.

\section{El franquismo en la editorial Vicens Vives}

Los contenidos de esta primera editorial objeto de crítica se caracterizan por seguir una línea ideológica de corte liberal en el área de Ciencias Sociales, Geografía e Historia (Castillejo Cambra, 2009). La dictadura de Franco se aborda en el tema veinte del libro de texto, bajo el título España durante el franquismo. La división de la unidad temática se estructura en cinco partes diferenciadas con varias subdivisiones en cada una de ellas: una introducción, la posguerra (configuración de la dictadura, miseria y autarquía), el desarrollismo (los cambios políticos y económicos y los cambios sociales), la oposición al franquismo (durante todo el período, dividido entre posguerra y los años sesenta) y el fin del régimen y la transición política.

Entendemos que la aproximación al franquismo en $4^{\circ}$ de ESO debe abordar los principales conceptos (saberes) sobre la temática para poder ponerlos en relación con otros contenidos procedimentales (saber hacer) y actitudinales (saber hacer para). Sin embargo, esto no es óbice para obviar contenidos bastante estudiados y consensuados por los especialistas, ni para la realización de afirmaciones e informaciones simplistas. Afirmaciones tales como que en FET y de las JONS "se agrupaban todos los vencedores de la Guerra" (Vicens Vives, 2001, p. 286) o que "los grupos que habian apoyado el Alzamiento Nacional [eran sólo]: la gran burguesía, el Ejército y la Iglesia” (Vicens Vives, 2001, p. 286), son fácilmente desmontables y criticables a la luz de las múltiples investigaciones que, durante las tres últimas décadas, se han realizado sobre este régimen político. Asimismo, creemos que no se explica con claridad el contexto y el porqué de diversos acontecimientos y transformaciones ideológicas y políticas, como que a partir de 1945 se fueran "eliminando los signos más claramente fascistas" (Vicens Vives, 2001, p. 286), o que "se intentó asegurar la continuidad del régimen después de Franco y, en 1969, las Cortes aceptaron al príncipe Juan Carlos de Borbón como sucesor a la Jefatura del Estado a título de rey" (Vicens Vives, 2001, p. 290).

En este sentido, creemos que podría ser interesante apuntar que, durante los primeros años de la dictadura, el régimen se debatió entre un proyecto de Estado nacionalcatólico -ideología de largo recorrido en la historia política española- frente a otro que promulgaba un Estado totalitario fascista. Entre ambos proyectos hubo confluencias y conflictos que desembocarían, por causas tanto internas como (sobre todo) externas, en el triunfo del proyecto nacionalcatólico sobre el defendido por el fascismo falangista. No se aporta una explicación del porqué se abandonan muchos de los 
rasgos fascistizados de la dictadura tras la caída del Eje, algo que resulta fundamental para poder entender la perdurabilidad del régimen político, así como no se habla en ningún momento de qué sectores del régimen eran los que proponían la continuidad del franquismo a través de una monarquía autoritaria, dando a pensar que todos los grupos políticos franquistas pensaban y apoyaban lo mismo. El nombramiento de Juan Carlos como rey supuso un triunfo del ala de Carrero Blanco y de los tecnócratas (sobre todo de la figura de López Rodó), pero había muchos otros sectores que no estaban de acuerdo con este hecho, por lo que no se debe presentar como un intento general de asegurar la continuidad del régimen.

No encontramos, a lo largo del desarrollo del texto, una mínima -o aunque sea intuidadiscrepancia entre pareceres políticos y tensiones ideológicas entre las diferentes derechas que componían el bloque político y social franquista. Han sido ampliamente estudiadas por los especialistas las confrontaciones simbólicas e ideológicas que, en el seno de FET y de las JONS, mantuvieron los carlistas de la Comunión Tradicionalista y los antiguos falangistas afines al ideal primorriverista, las cuales no se nombran ni tienen reflejo en el contenido de la unidad en ningún momento. Tampoco se presentan diferencias entre el ideal político de los monárquicos (no se diferencia entre carlistas y alfonsino-juanistas), los falangistas, los diferentes grupos católicos y las jerarquías de la Iglesia, etc. Parece como si todo el bloque fuera monolítico, cuyas decisiones eran tomadas al unísono a lo largo del desarrollo del período, cuando en realidad las evidentes transformaciones sociales, políticas, ideológicas y económicas que se suceden durante todo el régimen son consecuencia de las diferentes luchas internas entre los grupos políticos por alcanzar parcelas de poder y de las sucesivas selecciones políticas realizadas por Franco, con la finalidad de mantener siempre a salvo su omnímodo poder. La figura clave para el mantenimiento de la unidad entre todos los sectores siempre es el caudillo, su autoridad, el culto que todos los grupos le consagran a pesar de sus (a veces, incluso, casi insalvables) diferencias en lo ideológico.

También se obvia la importancia del Concilio Vaticano II para entender la diversidad ideológica que se fraguaría en el seno de la Iglesia católica española durante los años sesenta y setenta y el progresivo desmoronamiento del carácter monolítico que tenía la institución en España en los años cuarenta y cincuenta. Se obvia, asimismo, que una de las causas fundamentales para entender el desmantelamiento de la dictadura es el hecho de que una parte de la institución religiosa retire su legitimación y apoyo al régimen, porque -hasta entonces- la Iglesia no sólo apoyaba a la dictadura sino que era parte de la dictadura.

En definitiva, podemos señalar que el contenido de la unidad temática sobre la España de Franco en el libro de texto de la editorial Vicens Vives producido durante la LOGSE debería ser objeto de una profunda revisión para adecuarla al estado de los debates historiográficos de las últimas décadas, ya que, en los últimos treinta años, la temática ha sido objeto de un profundo avance en el conocimiento científico universitario acerca de las confrontaciones que se dieron en el seno del régimen y su importancia para entender los sucesivos cambios políticos, económicos e ideológicos.

\section{El franquismo en la editorial Anaya}

La segunda unidad didáctica objeto de análisis es la presentada por la editorial Anaya. Castillejo Cambra (2009) no especifica a qué corriente ideológica se asocia esta editorial, pero podemos aventurar que se posiciona en un liberalismo avanzado. En el libro de texto ofrecido por Anaya, el franquismo se estudia en el tema nueve, bajo el título España. La dictadura de Franco. La unidad se divide en ocho puntos con varias subdivisiones en cada uno: 1) los apoyos ideológicos y político-sociales de la dictadura; 2) la política interna de régimen; 3) la oposición a la dictadura y su represión; 4) la política exterior del régimen; 5) la evolución económica; 6) la sociedad y la población; 
7) la cultura y el arte y, por último, 8) Andalucía durante el régimen franquista. En todos los apartados se diferencia entre el primer y el segundo período de la dictadura.

En líneas generales y a nuestro juicio, se trata de una unidad correctamente estructurada y que profundiza en ciertos aspectos que eran obviados en el tema analizado del manual escolar de la editorial Vicens Vives. Comenzar el primer punto presentando los diferentes apoyos ideológicos y político-sociales del régimen favorece la desmitificación de la idea de que la dictadura era monolítica en lo que respecta a su naturaleza política. Sin embargo, y a pesar de diferenciar entre diferentes tradiciones ideológicas que confluyeron en el seno del régimen -Anaya destaca el fascismo, el nacionalcatolicismo, el tradicionalismo y la unidad y exaltación de la patria-, las presenta desde una mirada muy superficial y epidérmica. Por ejemplo, en el sub-apartado del fascismo se afirma que "Por influencia de esta ideología, todo el poder se concentró en la persona de Franco, 'Caudillo de España por la gracia de Dios" (Anaya, 2016, p. 216). Pero esta afirmación es una imprecisión, pues desde el falangismo se construyeron diversas concepciones sobre el caudillaje franquista ${ }^{8}$. Seguidamente, el libro de texto señala que el nacionalcatolicismo "Consistió en una estrecha relación entre el Estado y la Iglesia católica" (Anaya, 2016, p. 216), obviando a otros grupos políticos y otras corrientes ideológicas reaccionarias y contrarrevolucionarias, muy conservadoras y extremadamente nacionalistas, que también se incardinan en esta ideología, de larga tradición durante el siglo XIX español: monárquicos tanto alfonsinos como carlistas, antiguos miembros y grupos políticos de la CEDA, etc.

Tampoco encontramos en el desarrollo del discurso del texto una mención a las discrepancias y tensiones existentes entre las diferentes familias, grupos políticos y corrientes ideológicas del régimen. Asimismo, tiende a obviar la importancia del contexto externo y la presión de otros países a la hora de describir las sucesivas transformaciones y adaptaciones del régimen. En este sentido, podemos destacar afirmaciones como que "En 1942, ante la previsible derrota de los totalitarismos en la Segunda Guerra Mundial, Franco quiso dar una apariencia democrática al régimen" (Anaya, 2016, p. 218). Esto es una imprecisión; Franco ansiaba la victoria del Eje, pero tuvo que amoldarse constantemente a las presiones externas que recibía de Estados Unidos y Gran Bretaña, países de los que dependía en redes comerciales y de exportaciones. Si disimuló su afinidad con la Italia fascista y la Alemania nazi no fue más que por ese tipo de presiones. Asimismo, tampoco se destaca la importancia del contexto externo en los inicios de la etapa del desarrollismo. Se habla de la realización de un plan de estabilización que puso fin a la autarquía y de varios planes de desarrollo, pero se obvia que todos esos planes fueron propuestos, aconsejados y supervisados por el Fondo Monetario Internacional y el Banco Mundial, e incondicionalmente apoyados por Estados Unidos.

Aunque se observan constantes cambios en el régimen a lo largo del discurso, se hace hincapié en su inmovilismo ideológico, una imprecisión, ya que la fluctuación desde posiciones fascistas hasta nacionalcatólicas es muy evidente y ha sido ampliamente estudiada, por lo que se puede afirmar que la dictadura fue muy camaleónica en lo ideológico. Asimismo, se presenta a la Iglesia -en lugar de una parte de la Iglesia (concretamente la posconciliar)- como grupo opositor a partir de los sesenta, así como a los monárquicos, a los que iguala como grupo opositor externo con los republicanos. Lo cierto es que los monárquicos alfonsinos sólo mostraron cierta oposición a la muerte de Alfonso XIII, pasada la Segunda Guerra Mundial y cuando se cercioraron de que Franco no tenía intención de restablecer la monarquía.

En conclusión, señalamos que la unidad temática sobre la España franquista en el libro de texto de la editorial Anaya debería ser objeto de una moderada revisión para la adecuación de las imprecisiones en el conocimiento científico que hemos ido exponiendo en los párrafos anteriores.

\footnotetext{
${ }^{8}$ Este tema ha sido ampliamente estudiado por Saz Campos $(2003,2012)$.
} 


\section{El franquismo en la editorial Edelvives}

El tercer manual escolar objeto de análisis sería el propuesto por la editorial Edelvives. Castillejo Cambra (2009) tampoco especifica a qué corriente ideológica y tradición educativa se asocia esta editorial. Sin embargo, podemos aventurar que se posiciona en el humanismo cristiano, vinculado al Instituto de los Hermanos Maristas (grupo editorial Luis Vives). El franquismo se estudia en el tema diez, bajo el título La Guerra Civily el franquismo. La unidad se divide en tres puntos -1) La Guerra Civil; 2) El franquismo y 3) La cultura y el arte: de la República al franquismo- con cuatro subdivisiones en el segundo punto y dos en el tercero. Las cuatro subdivisiones del apartado del franquismo son: 1) La estabilidad de la dictadura: totalitarismo y autarquía; 2) La apertura del régimen al exterior; 3) El desarrollismo: los avances económicos; y 4) La crisis del franquismo, que componen siete páginas de la unidad que, junto a los puntos sobre arte en el franquismo, hacen quince. Asimismo, el tema quince del libro, dedicado a Andalucía en la Edad Contemporánea, trata el franquismo en Andalucía en el punto siete, bajo el título Andalucía bajo el franquismo.

Bajo nuestro punto de vista, se trata del texto sobre el franquismo más somero y con mayores errores e impresiones de los tres analizados, y el que menos focaliza la atención hacia conceptos tan complejos y fundamentales para poder entender el franquismo como totalitarismo o nacionalcatolicismo, que sólo son nombrados pero no explicados. A pesar de que contiene un (sub)apartado sobre la ideología y los símbolos franquistas, nada se explica sobre esto, mencionándose únicamente los símbolos de la Falange y la afirmación de que "todos los grupos políticos franquistas quedaron unificados en un nuevo partido: Falange Española Tradicionalista y de las JONS" (Edelvives, 2017, p. 234). Sin embargo, no se trata quiénes fueron esos grupos políticos, ni se explica la (sincrética) naturaleza ideológica y política del régimen, y tampoco encontramos ni rastro de tensiones entre las dos principales corrientes/tradiciones ideológicas: el fascismo falangista y los sectores nacionalcatólicos, tradicionalistas y contrarrevolucionarios ${ }^{9}$.

Se cuenta el franquismo como una historia sin tensiones, con pocas - casi nulas- referencias a la oposición. Y apenas nada se dice de la Iglesia, y absolutamente nada de los monárquicos -tanto alfonsinos como carlistas-, los grandes terratenientes, los militares y todo el bloque político-social franquista. El texto es una secuenciación de datos, fechas e hitos narrados de manera diacrónica y sin presentar intentos de explicación ni interpretación, con conceptos vacíos y, sobre todo, con situaciones sin actores. Un ejemplo de ello es la siguiente afirmación sobre la situación del gobierno a finales de los años cincuenta: "Franco destituyó a algunos miembros del Gobierno y nombró en su lugar a jóvenes economistas del Opus Dei -los tecnócratas o desarrollistas-, que diseñaron una nueva política" (Edelvives, 2017, p. 235). Pero ni antes ni en ese momento se aborda quiénes eran esos actores a quienes destituyó el dictador, a qué corrientes ideológicas pertenecían dentro de los imaginarios franquistas y qué significó eso para el régimen. No se pueden entender las sucesivas transformaciones sociales, políticas, económicas e ideológicas de la dictadura sin abordar este tipo de cambios que sólo son nombrados pero no explicados.

En lo referente a los planes de estabilización y de desarrollo, nada se dice de cómo se idearon, qué organismos internacionales participaron en su génesis y sólo se afirma que "convertirían a España en un país desarrollado, urbano e industrial" (Edelvives, 2017, p. 236). Nada se habla de conceptos tales como liberalización de la economía o abandono de los postulados antiliberales propios del

\footnotetext{
9 "El riesgo de un énfasis excesivo en minimizar la influencia fascista [en realidad la influencia de multitud de contenidos], sin un análisis en profundidad de la cuestión, estriba en que el alumnado puede percibir, en base al sentido común colectivo y el imaginario histórico-mediático imperante en nuestra sociedad, que el franquismo no fue tan malo como el malvado fascismo. Ello puede tener un efecto desculpabilizador, tanto del franquismo y del propio Franco como de sus apoyos y herederos sociopolíticos" (Fuertes Muñoz, 2018, p. 296), cuestión en la que coincidimos con el autor.
} 
primer período del franquismo, ni una mínima intuición de transformación ideológica del régimen. Tampoco se abordan los cambios culturales y sociales -más allá de la fuerte emigración al exterior y del éxodo rural- que trajo ese desarrollo, urbanismo e industrialización anteriormente citados. No se habla de la liberalización de las costumbres ni de los profundos cambios experimentados por la población y algunas instituciones claves para el mantenimiento (y posterior derrumbe) del régimen, como la Iglesia católica.

Con respecto a la represión, al fuerte autoritarismo y violencia empleados por el régimen, apenas nada se comenta y, sólo al final, en los años de crisis de la dictadura, se señala que el gobierno respondió con dureza a la ofensiva de grupos terroristas como ETA, FRAP y GRAPO. Asimismo, hay imprecisiones graves como la afirmación de que "en marzo de 1974 fue fusilado el militante anarquista Salvador Puig Antich" (Edelvives, 2017, p. 240), cuando en realidad éste fue ejecutado a garrote vil, siendo la última ejecución de la historia de España mediante ese sistema.

En la revisión de Vicens Vives y de Anaya afirmamos la necesidad de profundizar en ciertos aspectos. Pero lo cierto es que, en esta revisión crítica sobre el contenido del texto de Edelvives, creemos necesario realizar un profundo ejercicio de adecuación no sólo a los avances del conocimiento científico sino hacia la estructuración de los contenidos, ya que hay muchos y muy fundamentales y pertinentes que se obvian y son necesarios para poder explicar y entender la complejidad del régimen. Fuertes Muñoz señala que, al igual que en Vicens Vives y Anaya -y yo creo que en muchísima mayor medida-, "cabría profundizar en el análisis de las dos culturas políticas de los apoyos del franquismo, la fascista y la nacionalcatólica, pudiendo adoptar conceptualizaciones, como la de régimen 'fascistizado', más flexibles y capaces de sintetizar la complejidad y pluralidad de la naturaleza ideológica de la dictadura, pero también la permanencia del componente fascista hasta el final de sus días" (2018, p. 297).

En conclusión, señalamos que la unidad sobre el franquismo en el libro de texto de la editorial Edelvives debería ser objeto de una profunda, necesaria y urgente revisión de la estructura de contenidos, para la adecuación de las múltiples imprecisiones en el conocimiento científico y para rellenar los vacíos conceptuales y los sorprendentes silencios que hemos ido señalando, argumentando y exponiendo en los párrafos anteriores. Las omisiones de conceptos tan fundamentales, y que sí hemos visto expresados en los otros dos textos analizados, no contribuyen a una comprensión compleja, sistémica y holística de lo que fue y significó la dictadura. Ya decimos que muchas son realmente sorprendentes, sobre todo en un momento en el que acumulamos una vasta producción científica sobre el régimen de Franco. Omisiones que podrían entenderse como un discurso (por omisión) legitimador de la dictadura, minimizador de sus consecuencias y que contribuye a la adopción de una perspectiva acrítica en un alumnado que finaliza la educación obligatoria. Es un desafío necesario pues salvar esta grave deficiencia.

\section{Conclusiones}

Este análisis crítico realizado sobre el contenido de tres manuales escolares producidos para Andalucía por tres editoriales de tradiciones liberales y conservadoras ha puesto de relieve que el avance del conocimiento científico universitario sobre la dictadura de Franco de las últimas décadas no se ve reflejado en los contenidos de los libros de texto seleccionados. El tratamiento conceptual de este tema, conflictivo por su pertenencia a lo que se denomina como Historia del Tiempo Presente (Lemus López, 1998), se vuelve aún más conflictivo aún cuando lo producen líneas editoriales marcadas por dos tradiciones con cercanía ideológica para con determinados fundamentos del régimen político franquista. 
Entre los tres manuales escogidos para el análisis hay diferencias que hemos ido resaltando de forma individualizada, y se podrían evaluar en una escala de mayor a menor rigor científico. Sin embargo, lo que ponemos de manifiesto es que los tres textos presentan la necesidad de una revisión conceptual en torno a cuestiones fundamentales ampliamente estudiadas por los especialistas: el franquismo como régimen no monolítico en lo ideológico, atendiendo a las alianzas y tensiones entre tradiciones políticas a lo largo del período; diferencias y profundización en conceptos como franquismo, fascismo, fascistización o nacionalcatolicismo, atendiendo a la naturaleza híbrida y camaleónica de la dictadura; legitimación del régimen a escala internacional en base a los intereses del proyecto neoliberal norteamericano y evolución de la legitimación ofrecida por las diferentes sensibilidades de la Iglesia católica; e incluso poner de manifiesto la instrumentalización que los poderes de la dictadura pusieron en práctica con determinados complejos simbólicos como fiestas, rituales y la construcción y resignificación de mitos nacionales.

En este sentido, para abordar la tarea de la revisión de los contenidos convendría apoyarse en los trabajos de Di Febo (1988, 2004, 2016), Lemus López (1998), Thomàs Andreu (2001, 2016), Saz Campos (2003, 2012), Casanova Ruiz (2005, 2009), Box Varela (2008), Carr (2009) o Moradiellos García (2016), entre otros investigadores y especialistas sobre el franquismo, pudiendo servir la bibliografía que proponemos como base para una primera inmersión en el avance del conocimiento científico universitario de cara a la adecuación de los contenidos.

\section{Referencias}

Box Varela, Z. (2008). La fundación de un régimen. La construcción simbólica del franquismo. Tesis doctoral, Universidad Complutense de Madrid, Madrid, España. Disponible en: https://eprints.ucm.es/8572/

Braga Blanco, G. y Belver Domínguez, J. L. (2016). El análisis de libros de texto: una estrategia metodológica en la formación de los profesionales de la educación. Revista Complutense de Educación, 27(1), 199-218. doi: https://doi.org/10.5209/rev RCED.2016.v27.n1.45688

Campos Pérez, L. (2010). Los relatos de la nación. Iconografía de la idea de España en los manuales escolares (1931-1983). Madrid: CEPC.

Carr, R. (2009). España 1808-2008 (2a ed.). Barcelona: Ariel.

Casanova Ruiz, J. (2005). La Iglesia de Franco (2a ed.). Barcelona: Crítica.

Casanova Ruiz, J. y Gil Andrés, C. (2009). Historia de España en el siglo XX. Barcelona: Ariel.

Castillejo Cambra, E. (2009). Análisis del contenido ideológico de los manuales de Historia. Bordón. Journal of Education, 61(2), 45-57. Disponible en: https://recyt.fecyt.es/index.php/BORDON/article/view/28719

Centro de Investigación MANES (2019). Disponible en: http:/ / www.centromanes.org/

Choppin, A. (1980). La historia de los manuales escolares. Una aproximación global. Revista Historia de la Educación, 9, 1-25.

Di Febo, G. (1988). La santa de la raza. Un culto barroco en la España franquista. Barcelona: Icaria.

Di Febo, G. (2004). La Cruzada y la politización de lo sagrado. En S. Sueiro Seoane (coord.), J. Tusell Gómez, E. Gentile, G. Di Febo (Eds.), Fascismo y franquismo cara a cara. Una perspectiva bistórica (pp. 83-97). Madrid: Biblioteca Nueva.

Di Febo, G. (2016). Franco y el nacionalcatolicismo: la construcción del carisma religioso. En E. Moradiellos García (dDir.), Las caras de Franco. Una revisión histórica del caudillo y su régimen (pp. 133-161). Madrid: Siglo XXI.

Díez Gutiérrez, E. J. (2014). La memoria histórica en los libros de texto escolares. Revista Complutense de Educación, 25(2), 393-409. 
Fernández Palop, M. P. y Caballero García, P. A. (2017). El libro de texto como objeto de estudio y recurso didáctico para el aprendizaje: fortalezas y debilidades. Revista Electrónica Interuniversitaria de Formación del Profesorado, 20(1), 201-217. doi: https://doi.org/10.6018/reifop/20.1.229641

Fuertes Muñoz, C. (2018). La dictadura franquista en los manuales escolares recientes: una revisión crítica. Revista Historia Autónoma, 12, 279-297. doi: https://doi.org/10.15366/rha2018.12.015

Glaser, B. G. y Strauss, A. L. (1967). The Discovery of Grounded Theory: Strategies for Qualitative Research. New York: Aldine.

Hamilton, D. (1990). What is a textbook? Paradigm, 3, 5-8.

Johnsen, E. B. (1996). Libros de texto en el calidoscopio. Estudio crítico de la literatura y la investigación sobre los textos escolares. Barcelona:

Pomares-Corredor.

Lemus López, E. (1998). Andalucía bajo el franquismo. En E. Lemus López, y L. Álvarez Rey (Coords.), Historia de Andalucía contemporánea (pp. 457-495). Huelva: Universidad de Huelva.

López Hernández, A. (2007). Libros de texto y profesionalidad docente. Avances en Supervisión Educativa. Revista de la Asociación de Inspectores de Educación de España, 6, 1-8.

Miralles Martínez, P., Molina Puche, S. y Ortuño Molina, J. (2011). La investigación en Didáctica de las Ciencias Sociales. Educatio Siglo XXI: Revista de la Facultad de Educación, 29(1), 149-173. Disponible en: http://didactica-ciencias-sociales.org/articulos archivos/2011INVESTIGACIoN-DCS-miralles.pdf

Mondragón Mullor, M. C. (2013). Enseñanza y aprendizaje de la gramática y ortografía en la Educación Secundaria Obligatoria a través de los libros de texto (Tesis doctoral). Universidad de Almería, Almería.

Moradiellos García, E. (2016). Caudillo de España. Franco, un dictador soberano y carismático. En E. Moradiellos García (Dir.), Las caras de Franco. Una revisión bistórica del caudillo y su régimen (pp. 29-95). Madrid: Siglo XXI.

Negrín, M. (2009). Los manuales escolares como objeto de investigación. Educación, Lenguajey Sociedad, 6, 187-208. Disponible en:

http://evirtual.uaslp.mx/Habitat/innobitat01/depto/Biblioteca/Ejemplo\%20de $\% 20$ manuales/ Manuales $\% 20$ escolares $\% 20$ como $\% 20 \mathrm{obj}^{2} \% 20 \mathrm{de} \% 20$ invest n06a 10 negrin.pdf

Prats, J. (2003). Líneas de investigación en didáctica de las ciencias sociales. Historia \&

Ensino. Revista do Laboratorio de Ensino de Historia, 9, 1-25. Disponible en: http://www.ub.edu/histodidactica/images/documentos/pdf/lineas investigacion didactica ci encias sociales.pdf

Prats, J. (2011). Criterios para la elección del libro de texto de historia. Íber: Didáctica de las Ciencias Sociales, Geografía e Historia, 18(70), 7-13. Disponible en:

http://www.ub.edu/histodidactica/index.php $\% 3$ Foption $\% 3$ Dcom content $\% 26 v i e w \% 3$ Darticl e\%26id\%3D149:criterios-para-la-eleccion-del-libro-de-texto-dehistoria $\% 26$ catid $\% 3$ D24:articulos-cientificos $\% 26$ Itemid $\% 3$ D118

Puelles Benítez, M. (1997). Estudio preliminar: política, legislación y manuales escolares (1812-1939). En J. L. Villalain, Manuales escolares en España, Tomo I. Legislación (1812-1939) (pp. 17-70). Madrid: UNED-MANES.

Puget, M. (1963). Le livre scolaire. Tendances, 22, 212-230.

Rodríguez Pérez, R. A. y Solé, G. (2018). Los manuales escolares de Historia en España y Portugal. Reflexiones sobre su uso en Educación Primaria y Secundaria. Arbor, 194(788). doi: https://doi.org/10.3989/arbor.2018.788n2004

Saz Campos, I. (2003). España contra España. Los nacionalismos franquistas. Madrid: Marcial Pons.

Saz Campos, I. (2012). Franco, ¿caudillo fascista? Sobre las sucesivas y contradictorias concepciones falangistas del caudillaje franquista. Historia y Politica, 27, 27-50. Disponible en: https://recyt.fecyt.es/index.php/Hyp/article/view/41233 
Strauss A. L. y Corbin J. (1998). Basics of qualitative research: Techniques and procedures for developing Grounded Theory. London: Sage.

The Georg Eckert Institute for Internacional Textbook Research (2019). The Institute. Disponible en: http://www.gei.de/en/institute.html

Thomàs Andreu, J. M. (2001). La Falange de Franco. Fascismo y fascistización en el régimen franquista: (19371945). Barcelona: Plaza y Janés.

Thomàs Andreu, J. M. (2016). Franquistas contra franquistas. Luchas por el poder en la cúpula del régimen de Franco. Barcelona: Debate.

Tosi, C. (2011). El texto escolar como objeto de análisis. Un recorrido a través de los estudios ideológicos, didácticos, editoriales y lingüísticos. Lenguaje, 39(2), 469-500. Disponible en: http://www.scielo.org.co/scielo.php?pid=S0120$\underline{34792011000200008 \& \text { script }=\text { sci abstract\&tlng }=\text { es }}$

Valls Montés, R. (2001a). Los estudios sobre los manuales escolares de historia y sus nuevas perspectivas. Didáctica de las Ciencias Experimentales y Sociales, 15, 23-36. Disponible en: https://ojs.uv.es/index.php/dces/article/view/2915/2487

Valls Montés, R. (2001b). Los nuevos retos de las investigaciones sobre los manuales escolares de historia: entre textos y contextos. Revista de Teoría y Didáctica de las Ciencias Sociales, 6. Disponible en:

http://www.saber.ula.ve/bitstream/handle/123456789/23960/rafael valls.pdf;jsessionid=C6F A1C84C973D12D17BC2B9C4AAC1ABA? sequence=1

Valls Montés, R. (2007a). La Guerra Civil española y la dictadura franquista: las dificultades del tratamiento escolar de un tema potencialmente conflictivo. Enseñanza de las ciencias sociales: revista de investigación, 6, 61-74. Disponible en: https://dialnet.unirioja.es/servlet/articulo? codigo $=2313291$

Valls Montés, R. (2007b). Las imágenes en los manuales escolares de Historia y las dificultades de su uso didáctico. Clio \& asociados: La historia enseñada, 11, 11-23. Disponible en: http://sedici.unlp.edu.ar/handle/10915/32682

Van Dijk, T. A. (1997). Racismo y análisis crítico de los medios. Barcelona: Paidós.

\section{Información sobre el autor}

Autor: José Carlos Mancha Castro

Institución: Universidad de Huelva

Email: jose.mancha@pi.uhu.es

ORCID: https://orcid.org/0000-0003-0092-4417 


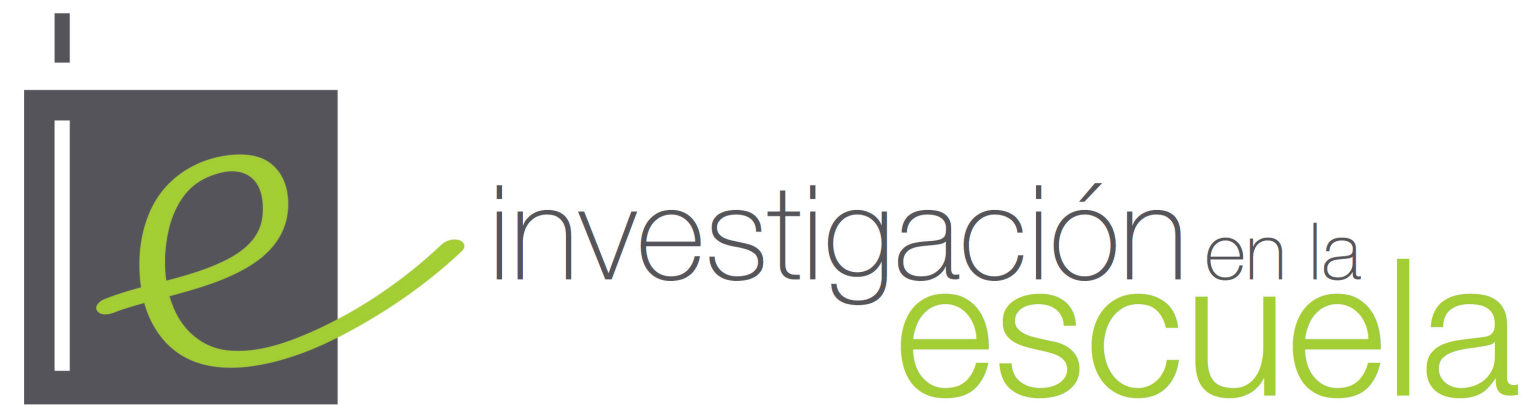

Revista académica evaluada por pares y de acceso abierto

Número 98

31 de julio de 2019

ISSN 2443-9991

(c) (i) (2)

Esta obra está bajo una licencia Creative Commons. Los/as lectores/as pueden compartir, copiar y redistribuir el material en cualquier medio o formato, así como adaptar, remezclar, transformar y construir a partir del material para cualquier propósito, incluso comercialmente. Para ello, deben de hacerlo bajo los siguientes términos: dando crédito de forma adecuada, brindando un enlace a la licencia e indicando si se han realizado cambios. Si se remezcla, transforma o crea a partir del material, debe distribuir su contribución bajo la misma licencia del original.

Más detalles de la licencia de CreativeCommons se encuentran en https://creativecommons.org/licenses/by-sa/4.0/deed.es

Cualquier otro uso debe ser aprobado en conjunto por el autor/es, o Investigación en la Escuela.

Uิ

Revista Editada por la Universidad de Sevilla. https://editorial.us.es/es/revistainvestigacion-en-la-escuela

Por errores y sugerencias contacte a secretaria@investigacionenlaescuela.es

La revista Investigación en la Escuela desde su origen en 1987 hasta su nº 87 (2015) fue editada por Díada Editora. 
